\title{
Development of IIS Distributed Hydrological Model (IISDHM) and its Application in Chao Phraya River Basin, Thailand.
}

\author{
Raghunath Jha*, Srikantha Herath ${ }^{* *}$, Katumi Musiake**
}

\begin{abstract}
A physically based distributed mathematical hydrological model has been developed. In this model, the hydrological processes of water movements are modeled either by finite difference representation of the partial differential equations of mass, momentum and energy conservation or by empirical equations derived from different research. Main processes of hydrological cycle, such as overland and river flow, unsaturated flow and ground water flow are modeled by St. Venant equation, Richard equation and Boussenq equation respectively. The model is applied in Ping catchment of Chao Phraya river basin, Thailand. The catchment area of the basin is 6,300 sq. $\mathrm{km}$. The results show the good agreement between simulated and observed hydrological responses. The preprocessing and post processing of the data are done in GIS. An interactive software has been developed for data input.
\end{abstract}

Keywords: distributed hydrological model, hydrological model, Thailand

\section{INTRODUCTION}

Numerous hydrolugical models have been developed in the past, but traditional models are lumped, i.e. they refer to spatially averaged condition of the basin. Furthermore, their parameters have no direct physical meaning and cannot be easily derived from measurable properties of the basin. In these circumstances, traditional models can be applied only as long as the river basin remains unchanged. Therefore, they cannot be used to predict the effects of changes in land use, such as deforestation, cultivation and irrigation. On the other hand a physically distributed model can predict hydrological effects by manmade changes to land use and other water use.

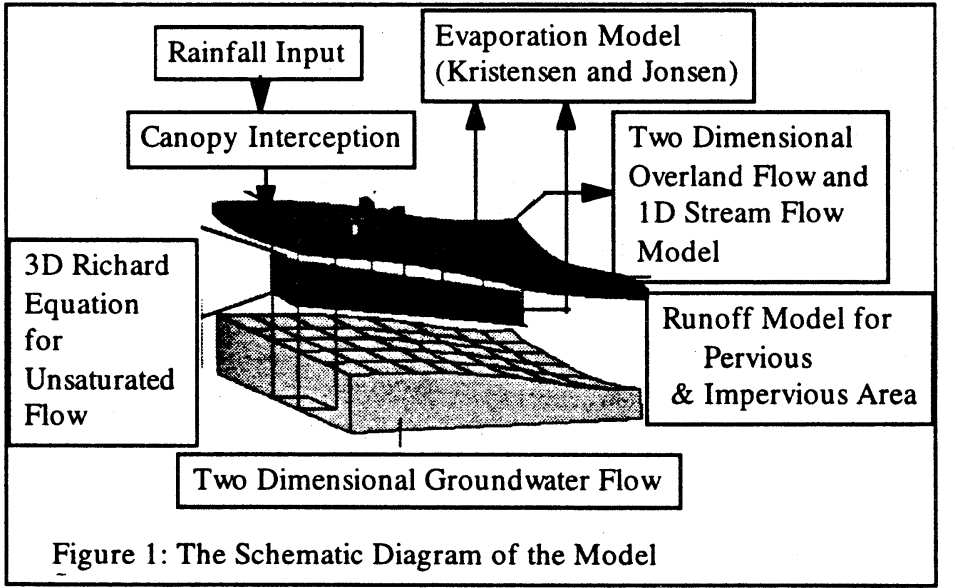

These models are thought to have an advantage over simple black box or even lumped physically based model in that, through their use of spatially distributed parameters which have physical significance, they don't require long term hydrological records for their calibration.

\footnotetext{
- Student Member, M. Eng., Institute of Industrial Science, University of Tokyo

** Member, D. Eng., Professor, Institute of Industrial Science, University of Tokyo 7-22-1, Roppongi, Minato-ku, Tokyo 106, Japan
} 
Due to rapidly increasing computational power and also, the developments of the geographical information system (GIS) and availability of digital terrain map (DTM), development and application of physically distributed model are becoming easy. There are now a number of such models, that are being used regularly, such as Systeme Hydrologique Europeen (SHE, Abbot et. al., 1986; Bathurst \& O'Connell, 1995), Institute of Hydrology Distributed Hydrological Model (IHDM, Calver and Wood, 1995 ). Due to one dimensional treatment of unsaturated flow, SHE model cannot be used to simulate the hilly terrain properly (Jha et al., 1995). Also this model does not give good results in large catchments. The IISDHM treats unsaturated zone 3-dimensionally, therefore, this model can be applied in any type of catchment. This model also solves the overland flow by two dimensional St. Venant equation by diffusion approximation, and thus can be used to simulate irrigation and floods.

\section{MODEL DESCRIPTION}

The model consists of four main components, i.e. interception, surface and river flow, subsurface flow and ground water, as presented in the Figure 1. Spatial distribution of catchment parameters, rainfall input and hydrological response are represented in the horizontal plane by an orthogonal grid network and in the vertical plane by a column of horizontal layers at each grid. The different process are described below:

\section{(2.1) Interception:}

The interception component calculates net rainfall reaching the ground through the canopy, the amount of water stored on the canopy and evaporation from the canopy. The interception process is modeled as in BATS (Dickinson et at. 1993). The canopy is considered to have a maximum surface storage capacity $S_{\max }$, which is filled by rainfall and emptied by evaporation and drainage. This capacity may be interpreted as the minimum depth of water required to wet all canopy surfaces. I is depth of water on the canopy and calculated as.

$$
I=C^{*} L A I \quad \text { (1) }
$$

Where C = Interception paramctcr $(\mathrm{mm}) ; \mathrm{LAI}$ - Leaf Area Index

The parameter $\mathrm{C}$ is dependent on vegetation. The evaporation from the canopy, $I_{-} E p$ is calculated as;

$$
I_{-} E_{p}=E_{p} \quad \text { if } I \geq S_{\max } \text { and } \quad I_{-} E_{p}=E_{p} * I / S_{\max } \quad \text { if } I<S_{\max }
$$

(2.2) Evapotranspiration

The actual evapotranspiration is calculated on the basis of potential evapotranspiration (directly input to the model) and actual soil moisture status in root zone. The model adopted is the one described by Kristensen and Jensen model (1971). The potential evapotranspiration is divided into actual transpiration and actual evaporation. The actual transpiration takes place within the root zone of the crop, while the actual evaporation takes place only on the top layer of the soil. The actual transpiration $E_{a t}$ can be calculate as :

$$
E_{a t}=f(L A I)^{*} f 2(\theta)^{*} R D F^{*} E_{p}
$$

where $f(L A I)=$ function of leaf area index; $f 2(\theta)=$ function of moisture content at root depth level; $E p=$ potential evapotranspiration; $R D F=$ function of root depth index.

The actual evaporation $E_{s}$, consists of a base evaporation and evaporation from a possible water reserve in the upper layer, if the vegetation cover does not restrict the energy penetration to the soil surface. Es is calculated as

$$
E_{s}=E_{p}{ }^{*} f 3(\theta)+\left(E_{p}-E_{a t}-E_{p}^{*} f 3(\theta)\right) f 4(\theta)(1-f 1(L A I))
$$

Where $f(\theta)$ and $f 4(\theta)$ are functions of soil moisture at top layer.

\section{(2.3) Over Land Flow}

Overland flow may generate either, when the rainfall rate exceeds the infiltration rate and ponding occur or when ground water level rises upto the ground surface. Overland flow is simulated in each grid square by solving the two dimensional diffusive wave approximation of St. Venant equation, which is written as:

$$
\begin{aligned}
& \frac{\partial h}{\partial t}+\frac{\partial(U h)}{\partial x}+\frac{\partial(V h)}{\partial y}=q \\
& \frac{\partial h}{\partial x}=S_{o x}-S_{f x} \quad \text { in } X \text { direction, and } \frac{\partial h}{\partial x}=S_{o y}-S_{f y} \quad \text { in } Y \text { direction }
\end{aligned}
$$

Where $\mathrm{h}$ is water depth; $U$ and $V$ are velocities in $X$ and $Y$ directions respectively; $q=$ net precipitation infiltration ; $S_{o x}$ and $S_{o y}$ are slopes in $X$ and $Y$ directions; $S_{f x}$ and $S_{f y}$ are energy slopes in $X$ and $Y$ directions. Applying Manning equation, i.e.

$$
U=1 / N_{x} h^{0.667} S_{s f x}^{0.5} \quad \text { and } \quad V=1 / N_{y} h^{0.667} S_{s y}^{0.5}
$$

where $N_{x}$ and $N_{y}$ are roughness coefficient in $X$ and $Y$ directions. 
When we put Equation (7) in Equation (5), the Equation (5) becomes non linear. It is difficult to find a stable solution for set of two dimensional non linear equations. To simplify the problem, we make following simplifications:

The Equation (5) can be written as;

$$
\frac{\partial h}{\partial t}+U \frac{\partial h}{\partial x}+V \frac{\partial h}{\partial y}=q
$$

Where $U$ and $V$ are calculated in the previous time step. The implicit finite difference form equations are written for all nodes and solved by successive over relaxation method (SOR) using Chebysher acceleration.

\section{(2.4) River Routing}

When Saint Venant equation together with the junction continuity and dynamic equations are employed to solve the river flow, an extensive amount of storage and CPU time are required. To reduce the this computational burden, kinematic wave approximation is used. In a distributed hydrological model, it is difficult to solve the dynamic equation because, most of time the tributaries have no water, where as dynamic equation is not applicable for dry bed conditions. The entire network of channels are solved here considering the mass balance at each junction. The governing equation is as follows;

$$
\frac{\partial A}{\partial t}+\frac{\partial Q}{\partial x}=q_{L}
$$

Where $q_{L}$ is lateral flow per unit length and per unit time.

Using Manning equation (7), the Equation (9) can be written in as

$$
\begin{aligned}
& \frac{\partial Q}{\partial x}+\alpha \beta Q^{(\beta-1)} \frac{\partial Q}{\partial t}=q_{L} \quad \text { (10) } \\
& \text { where } \alpha=\left(N_{x} p^{0.667} / S_{o x}^{0.5}\right)^{\beta} \quad \text { and } \beta=0.6
\end{aligned}
$$

Equation (11) is solved explicitly to get the river discharge at next point. The river routing starts from far upstream point and routed to the mouth of the river.

\section{(2.5) Subsurface Flow}

The subsurface flow component connects the surface flow and the ground water flow components. Soil moisture distribution in the unsaturated subsurface zone is calculated by solving three dimensional Richard equation. The $X$ and $Y$ components of the Richard equation are solved explicitly for previous time step. Soil moisture flux due to $X$ and $Y$ components, extraction of moisture for transpiration and soil evaporation are introduced as sink terms at the node points in the root zone. Infiltration rates are determined by upper boundary which may be either flux controlled i.e. net rainfall or head controlled, in the case of ponding. The lowest node point included in the finite difference scheme depends on the phreatic surface level and allowance is made for the unsaturated zone to disappear in cases where the phreatic surface rises to the ground surface. The governing equation is written as,

$$
C(\psi) \frac{\partial \psi}{\partial t}=\frac{\partial}{\partial z}\left[k(\psi) \frac{\partial \psi}{\partial z}+k(\psi)\right]+\frac{\partial}{\partial x}\left[k(\psi) \frac{\partial \psi}{\partial x}\right]+\frac{\partial}{\partial y}\left[k(\psi) \frac{\partial \psi}{\partial y}\right]-S
$$

Where $C(\psi)$ is specific moisture capacity function; $K(\psi)$ is unsaturated hydraulic conductivity and $S$ is source or sink term. Equation (12) is solve by implicit finite difference scheme.

(2.6) Ground water flow

The ground water level is modeled as multi layered two dimensional horizontal flow, where each layer could be either heterogeneous or homogeneous aquifer. The spatial and temporal variation of hydraulic head is simulated by non-linear Boussinesq equation for multi-layer leaky aquifers. The governing equation described as :

$$
S \frac{\partial h}{\partial t}=\frac{\partial}{\partial x}\left(T_{x x} \frac{\partial h}{\partial x}\right)+\frac{\partial}{\partial y}\left(T_{x x} \frac{\partial h}{\partial x}\right)+R-W+L_{\text {in }}-L_{\text {out }}
$$

Where $S$ is specific storage or specific yield, $h$ is ground water head, $T$ is transmissivity; $R=$ vertical recharge into ground water; $W=$ pumping or withdrawal from ground water; $L_{\text {in }}$ and $L_{\text {out }}$ are leakage in and out in a particular aquifer. In case of unconfined aquifer $T=K h$, where $K$ is saturated conductivity.

Equation (12) is solved by implicit finite difference approximation using SOR scheme. The interaction of the aquifer with the river system is calculated on the basis of the difference in river water levels and ground water table elevation.

\section{(2.7) Coupling}

All above mentioned process are computed parallel. The coupling module coordinates the parallel running of the other components by selecting their different time scales and organizing their data interchanges. Its functions include following; 
(a) Controlling the reading of the parameter sets and initializing the all computational variables. It reads the data such as topographic level, soils, land use, rainfall, meteorological station code, etc.

(b) Controlling the sequence in which each component is called to perform its computations.

(c) Controlling the exchange of data between components.

\section{(2.8) Data Preparation and Input}

In this model, the preprocessing and post-processing of the data are done in ARC/INFO, a GIS software. The model can directly read the output from GRID sub module of ARC/INFO, such as topography, land use soil type, rainfall code, meteorological station code, catchment boundary, etc. The time series data such as rainfall, potential evaporation are prepared in any spread sheet software. An interactive software has been developed to read the data input directly from the screen and write in a particular file and format, which will be the input to the model.

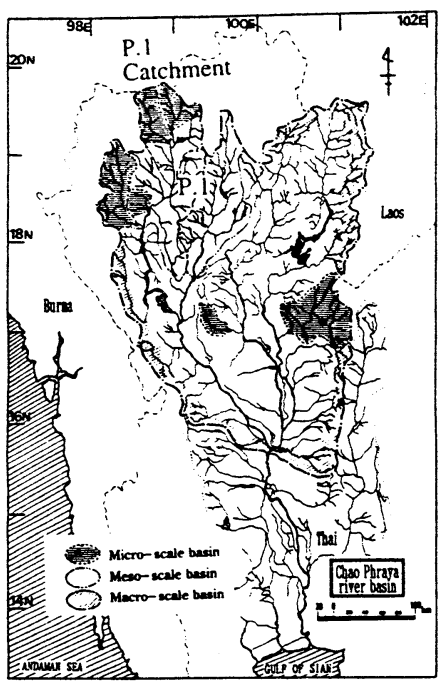

Figure 2 : Location map

\section{MODEL APPLICATION}

The above described model was applied to Ping river basin in Thailand. Ping river basin is a sub-catchment of the Chao Phraya river basin, which is the largest river basin in Thailand. Ping catchment is located at northwest side of Thailand (Fig. 2), between latitude $18^{\circ} 45^{\prime} \mathrm{N}$ to $19^{\circ} 45^{\prime} \mathrm{N}$ and longitude $99^{\circ} 45^{\prime} \mathrm{E}$ to $100^{\circ} 15^{\prime} \mathrm{E}$ with a catchment area of $6300 \mathrm{sq} . \mathrm{km}$. More than $75 \%$ of this catchment is mountainous and the elevations vary from $2200 \mathrm{~m}$ to $300 \mathrm{~m}$. The DEM was down loaded from United State Geological Survey (USGS) ftp site (http://edcwww.cr.usgs.gov/landdaac/30asdcwdem/30asdcwdem.html). The resolution of the DEM was 30 seconds, which is equal to $922 \mathrm{~m}$ in the study area. It was resampled to $1000 \mathrm{~m}$ and used to delineate the catchment boundary and to generate rivers using ARC/INFO (Fig. 3). The comparison between generated rivers and rivers from Digital Chart of the World (DCW) is shown in Figure 4. The comparison shows good agreement between two river systems. The landuse and soil map were taken from remote sensing and GIS laboratory of IIS, University of Tokyo. There were ten classes of land use, but due to nonavailability of data and less representation of some of classes, only two classes (forest and paddy field) are considered. Similarly, there are more than 40 classes of soil available, but the parameters of only two types of soil are available (Suntaree, 1993). Reclassification of soil map was done and only two classes were used in computation. The average rainfall in this catchment is 1250

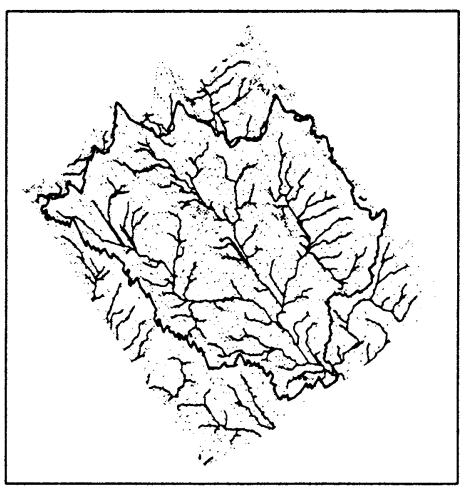

Figure 3 : DEM of Ping River Basin with Rivers $\mathrm{mm}$. Daily rainfall of 12 rain gauge stations are available, out of the 12 stations, hourly rainfall data of 3 stations are available. on the basis of hourly rainfall pattern, the daily rainfall is distributed to hourly rainfall data and used in the computation. Daily pan evaporation of one station is known which is used as potential evapotranspiration of whole catchment. Mae Ngat reservoir, which has a catchment area of $1281 \mathrm{sq} . \mathrm{km}$. and Mae Taeng irrigation weir (catchment area $1903 \mathrm{sq} . \mathrm{km}$.) are located north-eastern and north-west part of the catchment respectively (shown in Figure 4). The daily release from Mae Ngat reservoir and Mae Taeng weir are used as boundary conditions of the upstream of the these two rivers. The actual simulated area is $3116 \mathrm{sq}$. $\mathrm{km}$. 
Table 1 : Surface Storage and Leaf Area Index of Different Crops in Different Months

\begin{tabular}{|c|c|c|c|c|}
\hline Month & \multicolumn{2}{|c|}{ Storage (mm) } & \multicolumn{2}{c|}{ Leaf Area Index } \\
\hline & Paddy & Forest & Paddy & Forest \\
\hline Jul. & 60 & 15 & 1 & 5 \\
\hline Aug. & 60 & 15 & 2 & 5 \\
\hline Sep. & 60 & 15 & 3 & 5 \\
\hline Oct. & 100 & 15 & 4 & 5 \\
\hline Nov. & 100 & 15 & 5 & 5 \\
\hline Dec. & 60 & 15 & 1 & 5 \\
\hline Jan. & 20 & 15 & 1 & 5 \\
\hline
\end{tabular}

Table 2: The Water Balance in $\mathrm{mm}$

\begin{tabular}{|l|l|l|l|l|}
\hline Rainfall & Evaporation & $\begin{array}{l}\text { Surface } \\
\text { Runoff }\end{array}$ & $\begin{array}{l}\text { Ground } \\
\text { Water } \\
\text { Storage }\end{array}$ & $\begin{array}{l}\text { Soil } \\
\text { moisture } \\
\text { storage }\end{array}$ \\
\hline 883 & 555 & 94 & 124 & 110 \\
\hline
\end{tabular}

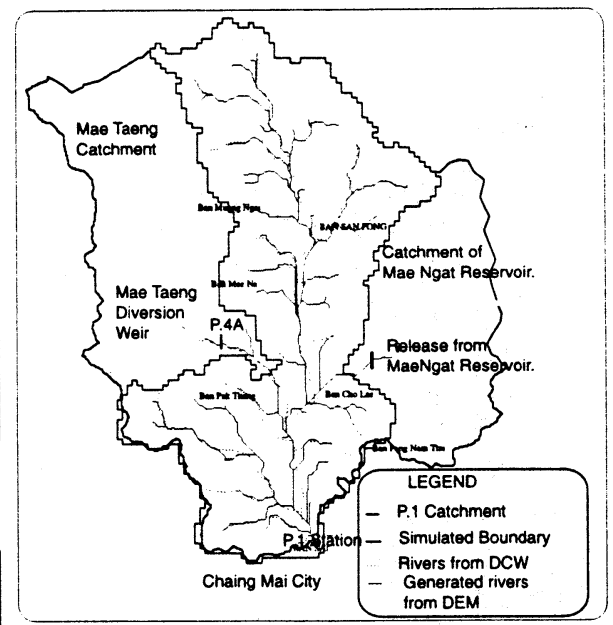

Figure 4 : Comperison Between Generated Rivers and DCW Rivers

\section{RESULTS AND DISCUSSION}

On the basis of

experience and trial simulation, the surface storage and leaf area index for different crops in different months have been decided, as shown in Table 1. A comparison of hydrograph at Chaing Mai (P.1) gauging station (shown in location map, Fig. 2) is presented in Fig. 5. from July 1992 to Dec. 1992 (six months period). The figure shows that

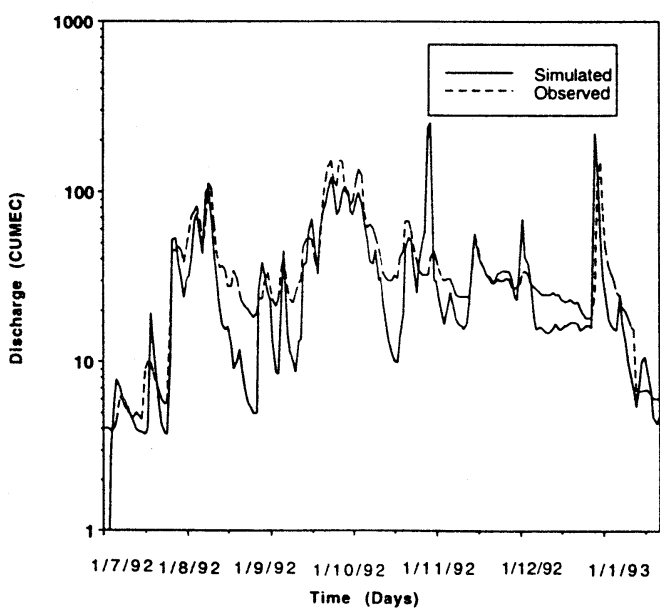

Figure 5: The Comparison Between daily Simulated and Observed Hydrographs

the observed and simulated hydrographs match reasonably well. The ground water depth at the end of Aug. 1992 and Nov. 1992 have been also shown in Fig. 6. The ground water figure shows the increase in ground water level from Aug. to Nov. Similarly, the monthly actual evaporation of Aug. and Nov. are shown in Figure 7. The figure shows that the total actual evaporation in Aug. is more than Nov.. The water balance of this period is shown in Table -2 .

The data requirements for IISDHM are substantial. The experience in Thailand indicates that the main part of data already exists with different Government and non-government organization such as departments of irrigation, meteorological, mines and universities. The total computational time taken for simulating 3116 sq. $\mathrm{km}$. catchment at $1 \mathrm{~km}$ mesh and 1 hour time resolution for seven months was about 3.5 hours in a DECALPHA vt-300 computer running Windows NT. The computational power available currently shows that application of distributed catchment models to large catchment is possible operationally. The IISDHM has been successfully applied in the Ping river basin, Thailand. However, to check the universal applicability of the model, this model should be applied in different countries.

\section{REFERENCES}

Abbot, M.B, Bathurst, J.C., Cunge, J. A. O' Connell, P. E. and Ramussen, J., 1986, An introduction to the European Hydrologic System (SHE), J. Hydrology 87, pp.45-59. 

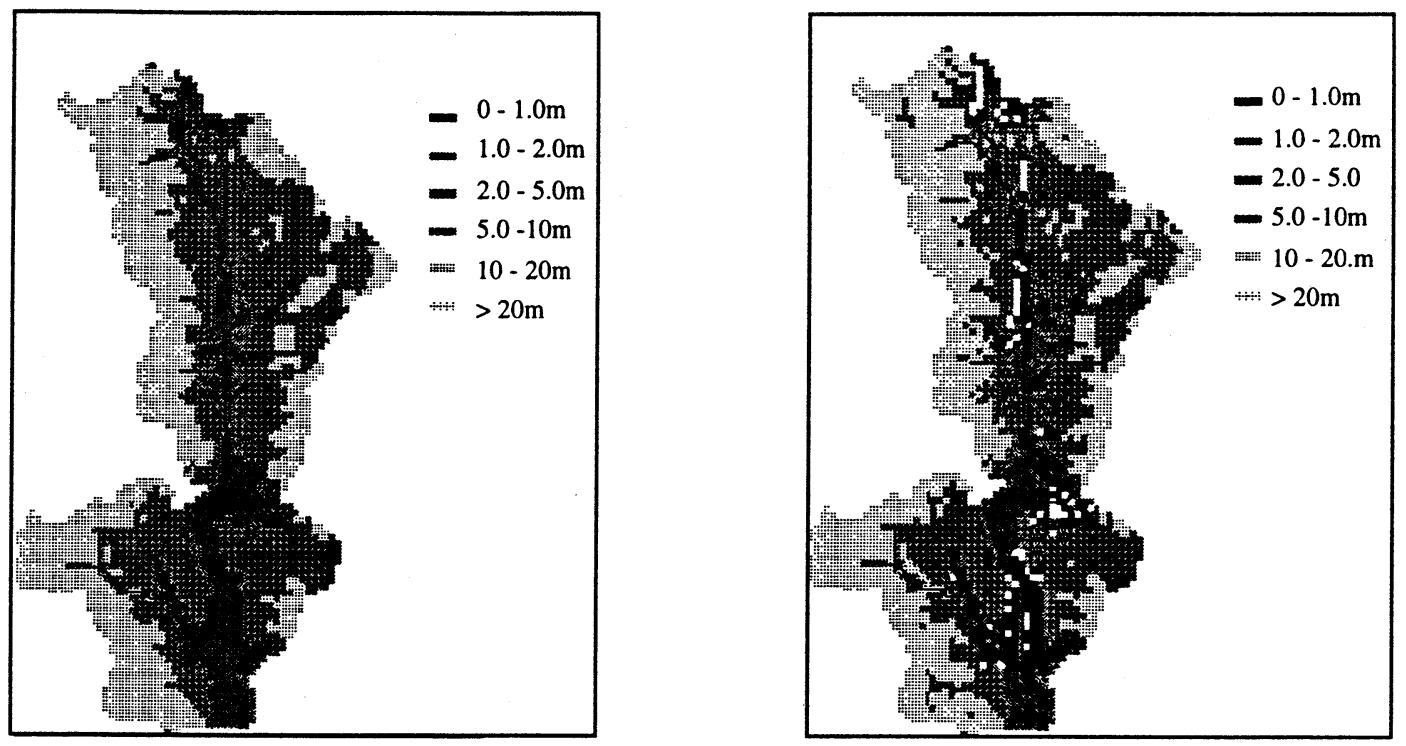

Figure 6 : The Ground Water Depth in Months (a) August and (b) November
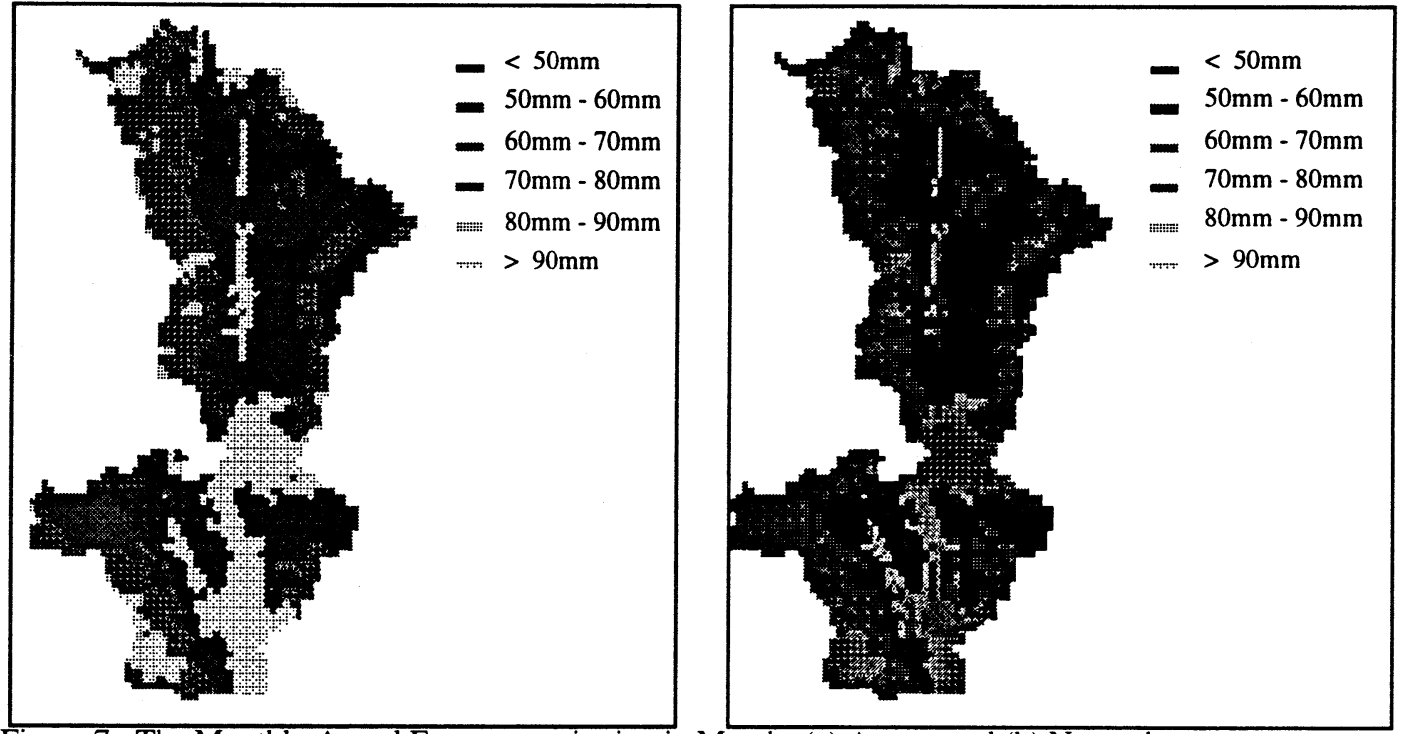

Figure 7 : The Monthly Actual Evapotranspiration in Months (a) August and (b) November

Bathurust , J.C., and O'Connell, P. E., 1992, The Future of Distributed Modeling; the System Hydrologic Europeen, Hydrol. process., Vol. 6. pp. 265-277.

Calver, A. and Wood, W. L., 1995, The Institute of Hydrology Distributed Model, in V. P. Singh (Ed.), Computer Models of Watershed Hydrology, Water Resources Publication, Colorado, pp. 595-626

Diskinson, R.E., Henderson-Sellers, A., and Kennedy, P. J. , 1993, Biosphere Atmosphere Transfer Schemes (BATS) version le, as coupled to the Community Climate Model. NCAR Technical Note NCAR/TN387+STR, National Center for Atmospheric Research, Boulder ,CO.

Jha, R., Herath, S., and Musiake K., 1995, Application of SHE model to Japanese Catchments, Proceedings of 1995 Annual Conference, Japan Society of Hydrology and Water Resources. pp. 162-16

Kristensen, K.J. and Jensen, S.E. (1975), A Model for Estimating Actual Evaporation from Potential Evaporation, Nordic Hydrology, Vol. 6. pp. 70-88.

Sutaree, Y., 1993, A Catalogue of Water Retention Functions of Major Soil Series of Thailand, Department of Soil Science, Kasetsart University, Kamphaeng Saen, Bangkok, Thailand. 